\title{
城市规划设计和建筑设计的关系
}

\author{
丁强
}

涡阳县城乡规划服务中心，安徽 涡阳 233600

[摘要]近年来, 我国社会经济水平得到了显著的提升, 从而推动了民众生活水平的提高, 这样就使得人们对生活环境提出了 更高的要求。城市规划工作其最为主要的目的就是推动社会和经济的发展，为城市发展确定准确度额方向，为民众创造良好 的生活环境, 提升城市资源的利用效率。就城市建筑来说, 其侧重研究的是建筑, 而城市规划能够为这项工作的开展给予良 好的辅助。换句话说, 城市建筑设计务必要与城市规划设计保持统一, 这样才可以将城市建筑在城市文明建设中的作用充分 的施展出来。

[关键词]城市规划设计; 建筑设计; 联系

DOI：10.33142/sca.v3i5.2262 中图分类号: TU984.1;TU201 文献标识码: A

\section{Relationship between Urban Planning and Architectural Design}

\author{
DING Qiang
}

Guoyang Urban rural planning service center, Guoyang, Anhui, 233600, China

\begin{abstract}
In recent years, Chinese social and economic level has been significantly improved, which promotes the improvement of people's living standards, which makes people put forward higher requirements for living environment. The main purpose of urban planning is to promote social and economic development, determine the accuracy of urban development, create a good living environment for the people and improve utilization efficiency of urban resources. As far as urban architecture is concerned, its emphasis is on architecture and urban planning can give good assistance to this work. In other words, urban architectural design must be consistent with urban planning and design, so as to give full play to the role of urban architecture in urban civilization construction. Keywords: urban planning and design; architectural design; connection
\end{abstract}

\section{引言}

城市的良好发展是需要城市规划设计和建筑设计加以辅助的, 为了能够从整体上提高城市的综合发展空间, 促进 民众生活水平的提升, 我们需要从多个角度入手来提高城市规划设计的整体水平, 综合建筑设计来全面推进城市综合 建设工作。在最近的几年时间里, 我国社会经济水平得到了显著的提升, 促进了人们生活水平的不断提高。在这种形 势下人们对生活的环境提出了更高的要求, 所以要想保证城市能够持续稳定的综合发展, 最为重要的就是需要切实的 运用最先进的设计理念和设计方法来提高城市规划设计的整体水平, 针对建筑设计进行优化和创新, 推动城市建筑设 计行业的良好发展。

\section{1 浅析城市规划设计与建筑设计间的区别}

总的来说，城市规划设计与建筑设计二者之间存在明显的差别，在实施整体设计工作的时候，务必要将自身所拥 有的优越性充分的发挥出来。因为建筑设计会受到多方面因素的影响, 从而导致后期指导工作的开展, 务必要对设计 目标加以深入的了解, 并且还需要将设计的意图与实际情况充分的结合, 将设计所具有的实际价值更好的显现出来 ${ }^{[1]}$ 。 其次, 建筑设计对于技术模式以及设计理念要求较高, 其中最为关键的就是需要确保设计具有良好的实用性。建筑设 计与城市规划设计二者在设计理念方面具有突出的差异性, 城市规划设计通常都会站在发展的角度来进行设计, 确保 设计结果与社会发展相一致。再有, 这几工作人员还应当充分结合社会发展形式针对建设设计理念以及设计的意义进 行深入的分析研究, 不断的提升设计的整体水平。最后, 综合实际情况来说, 二者在设计方面还存在巨大的差别, 在 实际开展规划设计的时候, 务必要进行全面的分析研究, 这样才能确保设计结果具有良好的可行性 ${ }^{[2]}$ 。

\section{2 城市规划设计与建筑设计的关系}

（1）城市规划设计的效果往往会与后期城市化建设工作的开展情况存在一定的关联, 所以需要由专业人员对城市 规划设计建设方案加以综合评价, 充分结合各方面实际情况来对城市规划设计方案的实用性进行判断, 这是现如今使 用最为频繁的评估方式。首先, 工作人员需要对城市发展目标以及发展规划进行全面的掌握, 对于人们生活的实际需 
要加以了解, 并在上述工作的基础上, 编制完善的城市规划设计方案, 针对城市所有基础设施, 功能设备以及各个空 间区域综合分类组合, 将其效能充分的施展出来, 促进城市建设现代化水平的不断提升。其次, 综合各方面实际情况 针对城市规划设计进行有效的调整, 从各个角度对建筑设计实施全面的分析研究, 针对城市规划设计工作中的重点加 以高效的树立, 确定规划地区的规划时间点。最后, 针对建筑设计的实用性以及可行性加以综合分析研究, 制定恰当 的控制目标, 针对城市规划设计以及工作实施计划加以深入的分析研究, 确保各项工作能够按照既定的计划按部就班 的进行 ${ }^{[3]}$ 。

（2）城市规划设计工作的开展所侧重的对象整个城市，结合现实情况以及各个功能空间以及基础设施进行全面深 入的研究分析, 保证功能空间划分的合理性和科学性, 推动城市现代化建设工作的全面开展。而建筑设计所针对的对 象是建筑结构自身结构设计、施工材料的挑选以及建筑风格的展现等加以合理的设计, 促进建筑结构综合性能的提升。 就设计内容方面来说, 二者都需要针对设计空间、设计对象的结构形式以及基础设施等不同的方面加以综合分析, 并 且建筑设计工作的开展务必要将城市规划设计内容当作是设计的主要参考, 针对城市规划设计中包含的所有工序加以 全面的了解, 并且严格遵照城市规划设计规范标准来落实各项设计工作 ${ }^{[4]}$ 。其次, 在我国社会经济飞速发展的影响下, 使得我国城市化建设工作得到了全面的开展, 从而推动了城市规划设计朝着智能化、精细化的方向迈进, 建筑设计务 必要顺应时代的发展, 切实的对建筑设计技术水平加以提升。借助城市规划设计与建筑设计二者所存在的关联, 将建 筑设计转变为促进城市规划设计不断发展的基础动力, 充实城市规划设计内容, 促使我国城市化建设工作得以全面的 进步。

（3）城市规划设计与建筑设计二者相互影响, 相互促进。首先各个地区环境情况以及气候情况都是不一样的, 所 以城市规划设计以及建筑设计都是会存在一定的差异。就城市风格来说务必要全面的进行深入的分析研究, 促使设计 工作人员能够形成良好的设计理念, 从而更好的对城市地理形态与建筑风格二者之间加以调节, 将城市中所有重点要 素加以整合, 将原本抽象的设计转变为具有良好设计成果。其次, 在实施城市规划设计工作的时候, 需要针对建筑设 计加以综合分析研究, 以城市规划设计为基础, 综合建筑缝合以及各方面需求, 制定出完善的建筑设计方案, 在设计 中更好的将城市特色呈现出来。

\section{3 提升城市规划设计与建筑设计综合水平的措施}

\section{1 以城市规划设计方向为参考}

在实际开展城市规划设计和建筑设计工作的之后, 最为重要的就是需要确定城市发展趋势, 并且要以提高城市综 合建设水平为核心, 切实的运用最先进的设计理念和设计方法, 结合城市整体发展情况以及城市规模, 对城市空间加 以合理的划分 ${ }^{[5]}$ 。

\section{2 加强设计质量控制}

为了全面提升城市的未来发展空间, 需要提升设计内容的合理性, 做好充分城市规划设计的同时, 多方面的考虑 城市的交通、供水、电力、通讯等多个方面的内容, 建设服务型社会。另外还需要对设计方案的内容进行全面的控制, 结合设计者自身的看法, 让专家对设计方案进行全面的评估。综合考虑设计中的环境因素, 提升建筑设计的综合经济 效益, 减少环境污染, 提升环境与城市的和谐相处。还可以结合建筑设计内容, 建立有效的评审机制, 提升设计方案 的评审水平，确保为两者的和谐发展提供保障，促进全面和谐发展，为建筑行业提供更好的发展空间。

\section{4 结语}

在社会经济水平不断提升的带动下, 使得我国加快了城市化建设的步伐, 这样就将城市规划设计与建筑设计在城 市化建设工作中的作用充分显现了出来, 使得人们对这两项工作越发的重视, 并且也推动了整个国家的建筑工程行业 的快速发展。只有将城市规划设计与建筑设计二者相互结合, 统一发展, 才可以为城市建设工作的大范围铺展开展创 造良好的基础。但是如果我们不能对二者的关系进行合理的处理, 那么也可能会激化二者的矛盾, 所以我们需要切实 的转变以往落后的思想关联，从各个角度入手来提高整个建筑工程行业的综合实力，推动社会和谐发展。

\section{[参考文献]}

[1]徐燕青,张苏俊.浅论城市规划设计与建筑设计的联系与协调发展 $[\mathrm{J}]$. 绿色环保建材, 2018 (09) : 75-78.

[2]壁静. 城市规划设计与建筑设计的联系与协调发展 [J]. 建材与装饰,2016(16): 118-119.

[3] 张季芳. 城市规划设计与建筑设计的关系探究 [J]. 低碳世界, 2016 (09) : 143-144.

[4]宋超.刍议城市规划设计与建筑设计的关系 $[J]$. 科技展望, 2015,25(20): 22-24.

[5] 薛静,余翔. 城市规划、城市设计和建筑设计的关系 [J]. 天然气与石油, 2010, 28 (02): 59-62.

作者简介: 丁强 (1977.9-), 男, 安徽建筑工业学院, 城市规划专业, 涡阳县城乡规划服务中心副主任, 高级工程师。 